\title{
De Praça das Verduras a Chá-Chá-Chá: imagens de um espaço público em contínua degradação
}

\section{From Vegetables Square to Cha-Cha-Cha: images of a continuing deterioration on public space}

Leonardo de Vasconcellos Silva - Mestre em Planejamento Regional e Gestão de Cidades pela Universidade Candido Mendes (UCAM)/Brasil-Rio de janeiro-Campos. E-mail: leosilvafoto@ gmail.com

Elis de Araújo Miranda - Geógrafa. Doutorado em Planejamento Urbano e Regional pela Universidade Federal do Rio de Janeiro (UFRJ)/Brasil-Rio de janeiro-Rio de Janeiro. E-mail: elismiranda10@gmail.com

\section{Resumo}

A partir de um conjunto de imagens foi possível reconstituir os contextos de produção e contínua deterioração de um espaço de convivência pública no centro histórico da cidade de Campos dos Goytacazes, no Norte do Estado do Rio de Janeiro. Da Praça das Verduras, um espaço de convivência do século XIX, ao ChaCha-cha, outro espaço de convivência no século XX, ou o que restou das seguidas intervenções urbanísticas municipais. Assim, importa neste trabalho, apresentar o método de elaborar uma reconstituição espacial por meio da pesquisa da produção fotográfica.

\begin{abstract}
From a set of images was possible to reconstruct the contexts of production and steady deterioration of a public living space in the historic city of Campos dos Goytacazes, the Northern state of Rio de Janeiro. Vegetables Square, a living space of the nineteenth century, the Cha-Chacha, another living space in the twentieth century, or what was left of the municipal urban interventions followed. This work presents a methodology to develop a space reconstruction through research of photographic production.
\end{abstract}

\section{Palavras-chave}

Imagem. Espaço Público. Campos dos Goytacazes.

\section{Keywords}

Image. Public Space. Campos dos Goytacazes. 


\section{INTRODUÇÃO}

Apesar dos esforços descontinuados e pontuais, o centro histórico da cidade de Campos dos Goytacazes, no norte fluminense, passou por sucessivas transformações. As áreas de convivência, os monumentos e os prédios históricos são relegados a plano secundário por seus proprietários e, ao mesmo tempo, negligenciados pelo poder público municipal que não possui uma política de estímulo que atenue a degradação progressiva a que estão sujeitos.

Responsabilizar exclusivamente a municipalidade por esses males em nada ajudará na formação de uma visão crítica que permita enxergar a importância de manter este legado para as gerações futuras. Embora tardio, o esforço da prefeitura para dotar a cidade de seu primeiro espaço de preservação da memória deve ser reconhecido. O Museu de Campos dos Goytacazes será instalado em um prédio que originalmente foi a residência do Visconde de Araruama, destacado ator no processo de desenvolvimento da cidade durante o século XIX. Após sua morte, o solar foi adquirido para sediar a Câmara Municipal, a sede da Prefeitura e as suas secretarias. Por estar localizada na principal praça da cidade, a praça de S. Salvador, ponto de convergência de grande parte da população que transita por aquele trecho do núcleo central, o prédio onde futuramente será implantado o museu deve confirmar o lugar de destaque que ocupa na paisagem urbana.

A recente reforma a que a referida praça foi submetida, realizada com o intuito de modernizá-la, acabou descaracterizando-a como espaço de sociabilidade, causando estranheza aos seus habituais frequentadores que não mais a reconhecem como tradicional ponto de encontro. Assim como a praça da matriz, outros espaços de sociabilidade na cidade de Campos dos Goytacazes vêm sendo desfigurados e/ou desaparecidos, como a Praça das Verduras que trataremos neste texto.

Assim, a partir da leitura da paisagem, da produção de imagens da paisagem atual e da pesquisa iconográfica, buscando identificar imagens desta mesma praça produzidas em diferentes momentos históricos, pretende-se discutir os projetos de intervenção em centros históricos. Neste caso, demonstra a produção de um espaço de convivência coletiva passa, a partir da intervenção pública, a ser um espaço elitizado e ao longo de cinco décadas este mesmo espaço é novamente transformado, com uma nova configuração e novos usos. A metodologia utilizada encontra-se de acordo com as orientações da Geografia Cultural que busca na produção de imagens a reconstituição de contextos geo-históricos e com isso pode abrir caminho para os métodos de intervenções em espaço coletivos sem com isso o coletivo tenha se manifestado.

Novos Cadernos NAEA • v. 16 n. 1 • p. 191-210 • jun. 2013 


\section{A PRAÇA DAS VERDURAS COMO ESPAÇO DE SOCIABILIDADE}

A Praça das Verduras se destacava como referência na vida urbana da cidade quando surgiu a necessidade de se criar um espaço para mercadejar. Em ata de 15 de abril de 1850 a Câmara Municipal determinou que lá e ao "Largo do Capim" seriam os lugares ideais "para se venderem quaisquer quitandas, quer verduras, quer de outro gênero ou objeto". Como forma de dotar a cidade de melhores condições de comércio e ao mesmo tempo organizar o espaço público, o vice-presidente da província do Rio e Janeiro, o Visconde de Baependi, autorizou a contratação de uma companhia para a construção de um mercado público. O decreto $n^{\circ} 782$ de 1855, assinado pelo Visconde, afirma que:

A camara municipal de Campos fica autorisada a contratar com a companhia ou emprezario que maiores vantagens offerecer a construcção de um mercado público naquella cidade, mediante a concessão de previlegio por um prazo que não exceda a quarenta annos, findo o qual ficará o mercado encorporado aos proprios do municipio (BAEPENDY, 1985, p. 59).

Situada numa área comercialmente privilegiada, diversas foram as tentativas de tirar da Praça das Verduras a função de mercado (Figura 1). Entre as seguidas investidas promovidas no decorrer do século XIX, a que esteve mais próxima de alcançar êxito surgiu com a proposta de transferência do mercado para o Largo do Rocio. No entanto, quando em 1878 a Câmara determinou a mudança do local do mercado para o Rocio "oito proprietários e negociantes do Largo das Verduras fizeram uma representação, pedindo que não fosse efetivada a mudança que feria os seus interesses" (SOUZA, 1935). O Largo do Rocio era na realidade uma praça e não apenas um simples "largo" como era denominado. A proposta de transferir o mercado da "quitanda velha" para lá se deve ao fato de que a primeira ferrovia de Campos, inaugurada em 1873, ligando a cidade ao distrito de S. Sebastião, tinha naquele lugar a sua estação. Nenhum local era mais apropriado para a comercialização das mercadorias produzidas na baixada campista que a praça em frente à estação (Figura 2). Nesse mesmo prédio, que serviu como estação, funcionou no passado a Escola de Aprendizes Artífices e funciona atualmente a Faculdade de Direito de Campos. 
Figura 1: Carregadores em frente ao mercadinho da Praça das Verduras, c. 1890.

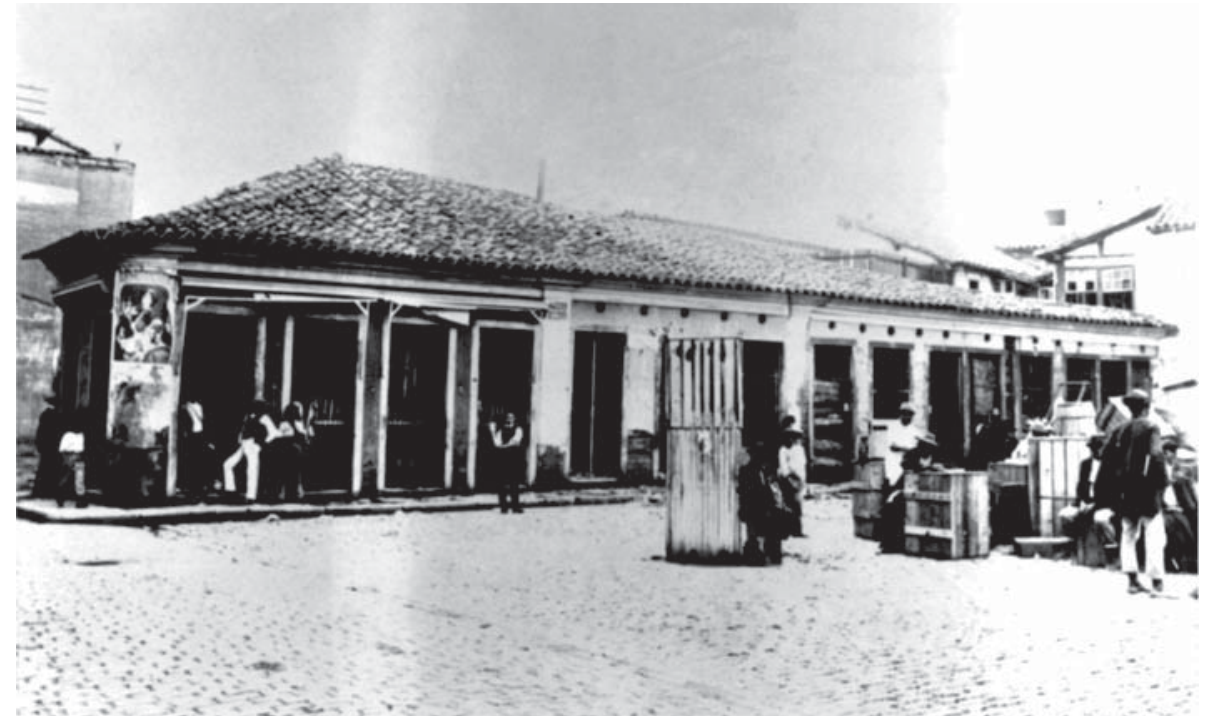

Fotógrafo: Autor não identificado

Coleção: Dr. Dario Marinho

Figura 2: Praça do Mercado no Rocio durante a enchente de 1906. À esquerda da imagem a Igreja de Santa Efigênia e à direita o sobrado onde funcionou a Estação da Estrada de Ferro Campos-S. Sebastião.

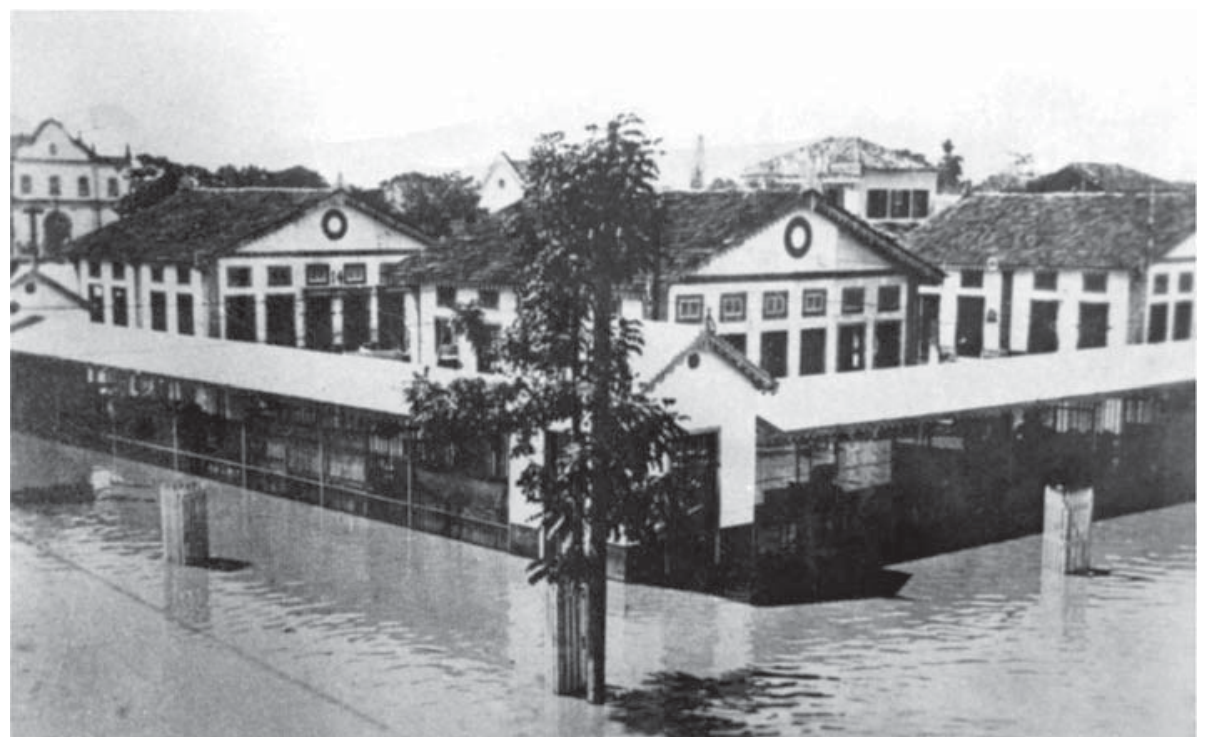

Fotógrafo: Alfredo Jabor

Acervo: Biblioteca Municipal Nilo Peçanha / FCJOL

Novos Cadernos NAEA • v. 16 n. 1 • p. 191-210 • jun. 2013 


\section{CAMPOS ADERE AO PROCESSO DE "HAUSSMANNIZAÇÃO”}

Maior fonte de recursos para Campos, a agricultura começou a dar sinais de debilidade no final do século XIX após a abolição da escravatura no Brasil. Buscando novas oportunidades, um enorme contingente de trabalhadores não qualificados, acompanhados de suas proles, deslocaram-se para os grandes centros. Por não serem absorvidos pelo mercado, vagavam pelas ruas centrais em busca de alguma atividade informal que pudesse lhes trazer sustento. Esses "desocupados", como eram chamados, promoviam todo tipo de baderna, afugentando do comércio mais refinado os potenciais clientes. O projeto de urbanização passou a ser a alternativa mais eficaz para revitalizar o centro comercial da cidade, acompanhando a tendência dos grandes centros urbanos (Figura 3), cerceando, ao mesmo tempo, a circulação desses frequentadores indesejados e dando uma nova feição a esta área da cidade.

Figura 3: Detalhe da PLANTA DA CIDADE - A Praça das Verduras ao centro, 1902

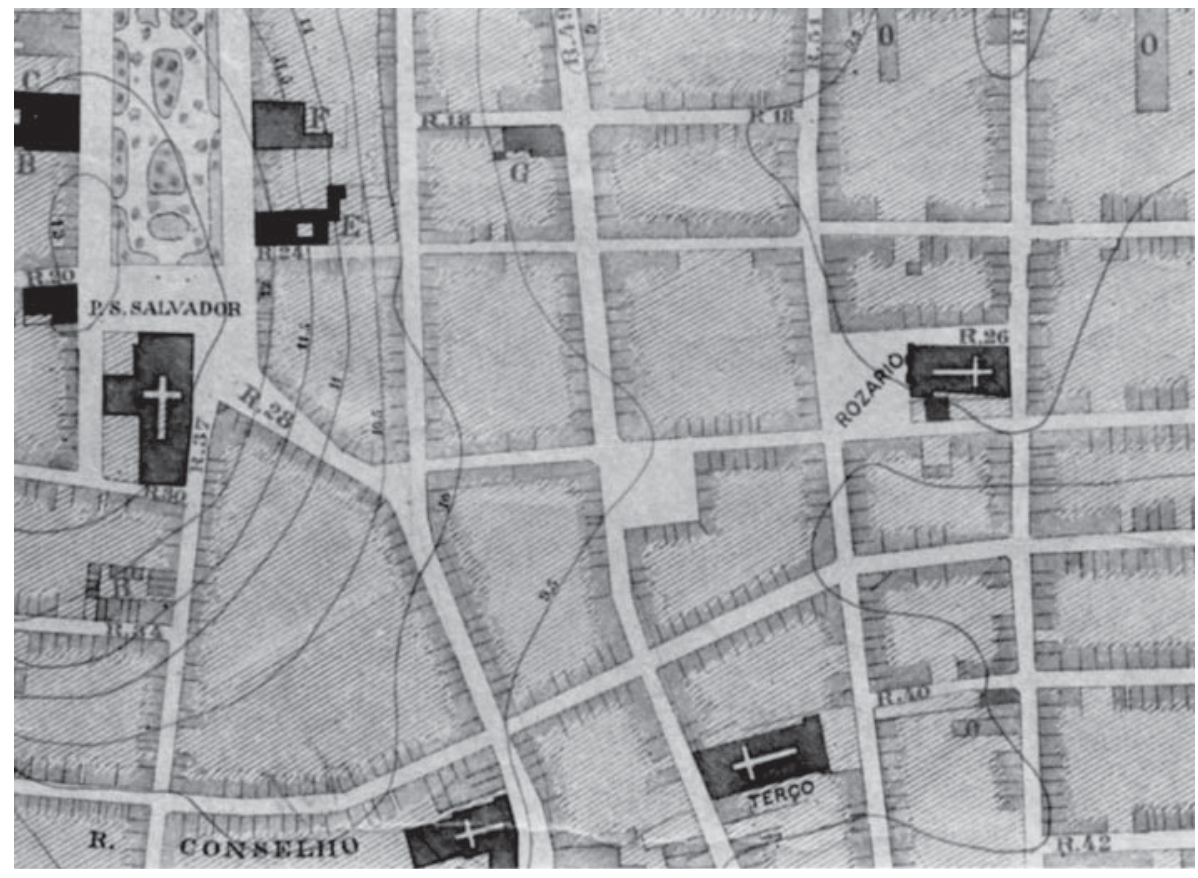

Autor: Francisco Saturnino Rodrigues de Britto

Acervo: Biblioteca Municipal Nilo Peçanha / FCJOL

No início da década de 1910, um grupo de políticos liderados pelo presidente do Estado, Oliveira Botelho, e pelo ministro da Agricultura, Pedro 
de Toledo, foi ciceroneado pelos usineiros em visita ao parque industrial açucareiro de Campos. Eles mostraram-se entusiasmados com a riqueza agrícola e com as máquinas de última geração que equipavam as unidades produtoras. Paradoxalmente, ao concluírem a visita ao município pelo centro urbano de Campos, os políticos não esconderam sua decepção com o aspecto atrasado da cidade, com prédios mal conservados, resquício do período colonial. Os próprios usineiros manifestaram esse sentimento no documento que produziram ao final da $4^{\mathrm{a}}$ Conferência Açucareira de Campos:

Os proprietários das uzinas de assucar de Campos, convencidos de que a situação actual da cidade não corresponde ao alto desenvolvimento da sua importante lavoura e das industrias agrárias, nem tão pouco às necessidades palpitantes da sua população, consoante à cultura moral e intellectual dos seus habitantes, justamente preocupados com os aspectos das construcçoes antigas da cidade e especialmente com a salubridade do nosso meio urbano, desejam solemnisar a reunião da $4^{\mathrm{a}}$ conferência assucareira propondo a indicação seguinte: Indicamos para solemnisar a alegria dos campistas pela reunião da $4^{\text {a }}$ Conferência Assucareira nesta cidade, se solicite do Dr. Oliveira Botelho, Presidente do Estado, a sua intervenção perante a Assembléia Legislativa para que, a título de contribuição addicional, seja votada uma taxa de $2 \frac{1}{2} \%$ sobre o imposto do assucar produzido no município de Campos (MONITOR CAMPISTA, 1916, capa).

O objetivo com a criação do imposto era transformar a cidade, modernizando-a com os lucros da exploração do seu solo. A nova configuração urbanística criada pelo Barão Haussmann em meados do século XIX na cidade de Paris, havia se tornado um modelo a ser copiado, independente de sua adequação, ou não, ao lugar proposto. Encarregado por Napoleão III de modernizar Paris após a Revolução de 1848, o Barão Haussmann privilegiou a estética em detrimento da sociabilidade existente, mandando demolir ruas antigas, pequenos comércios e moradias humildes, criando uma capital ordenada sob a orientação de um projeto geométrico que valorizasse as grandes avenidas (HALL, 2009 [1988]). A substituição de ruas estreitas e sinuosas por largos bulevares retilíneos e arborizados tornou-se um padrão adotado nas principais cidades e capitais do mundo. Essa tendência internacional não tardou a chegar ao Brasil, trazida pelas mãos do prefeito da cidade do Rio de Janeiro, Francisco Pereira Passos, que havia estudado na França durante o período de reformulação da sua capital e por Saturnino de Brito, o responsável pelas reformas em Campos. 


\section{ESPAÇOS PÚBLICOS DE CONVIVÊNCIA SOB UMA NOVA ESTÉTICA}

O desejo dos usineiros, somado ao consenso universal presente na formação intelectual do então prefeito de Campos, o médico Luiz Sobral, sinalizaram para a adoção da estratégia "haussmanniana" numa cidade de economia agrícola. Financiadas pelo novo imposto sobre uso do solo, as obras foram administradas pela Commissão de Saneamento, órgão criado para implementar as transformações necessárias sem estar obrigatoriamente atrelado à lentidão da máquina pública municipal. De certa forma todas as questões prioritárias foram atendidas, beneficiando principalmente os interesses da classe dominante. Além das estações de tratamento de água e esgoto, foi construído um novo dique para resguardar a cidade das sucessivas cheias (Figura 4); ruas estreitas e tortuosas, ainda do período colonial, foram calçadas com paralelepípedos.

O procedimento adotado no Rio de Janeiro por Pereira Passos, o "bota abaixo", também vigorou em Campos. Diversos estabelecimentos comerciais e residências tiveram que ser demolidos para permitir o alargamento e a retificação do traçado das ruas (Figura 5, 6, 7, 8 e 9); espaços públicos foram construídos ou remodelados, recebendo tratamento paisagístico e o sistema de transporte urbano foi incrementado com a implantação de linhas de bondes elétricos.

Figura 4: Praça das Verduras durante a enchente. A cheia do rio Paraíba em 1906 causou um grande número de mortes por leptospirose.

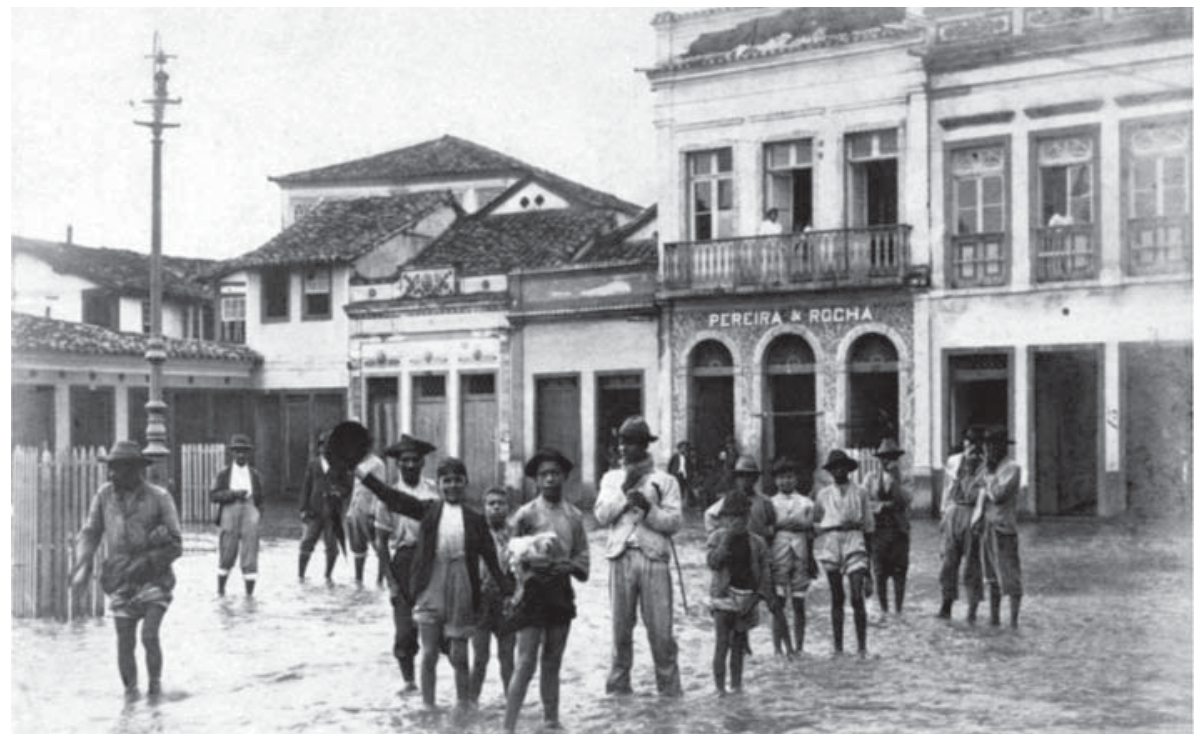

Fotógrafo: Francisco de Paula Carneiro

Acervo: Biblioteca Municipal Nilo Peçanha / FCJOL

Novos Cadernos NAEA • v. 16 n. 1 • p. 191-210 • jun. 2013 
Figura 5: Antiga fachada da livraria Ao Livro Novo voltada para a Praça das Verduras, antes do alargamento da Rua Sete de Setembro, c. 1910.

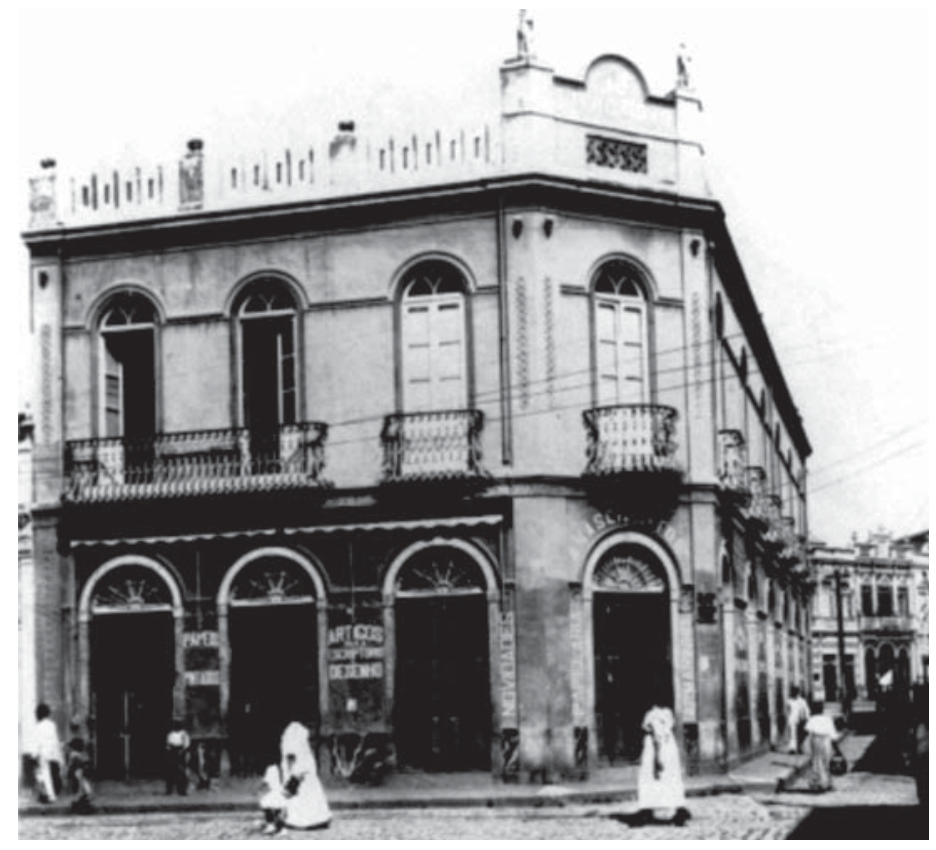

Fotógrafo: Autor não identificado

Coleção: Dr. Dario Marinho

Figura 6: Postal - Nova fachada da livraria Ao Livro Novo depois do alargamento da Rua Sete de Setembro, c. 1916.

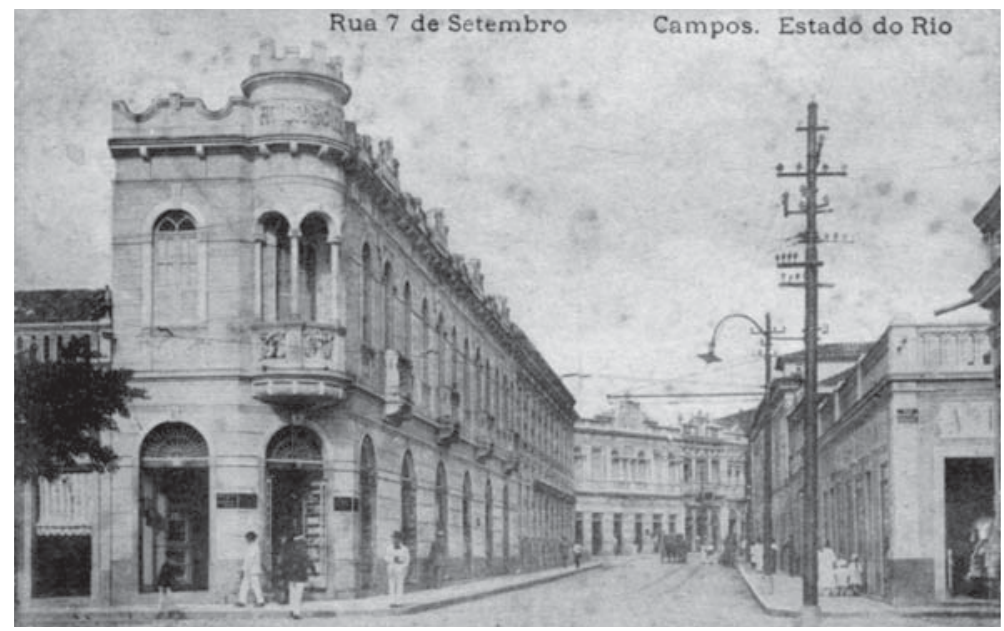

Fotógrafo: A. Ribeiro

Acervo: Biblioteca Municipal Nilo Peçanha / FCJOL

Novos Cadernos NAEA • v. 16 n. 1 • p. 191-210 • jun. 2013 
Figura 7: Destelhamento da livraria Ao Livro Novo para demolição parcial que permitiu o alargamento da Rua Sete de Setembro, c. 1914.

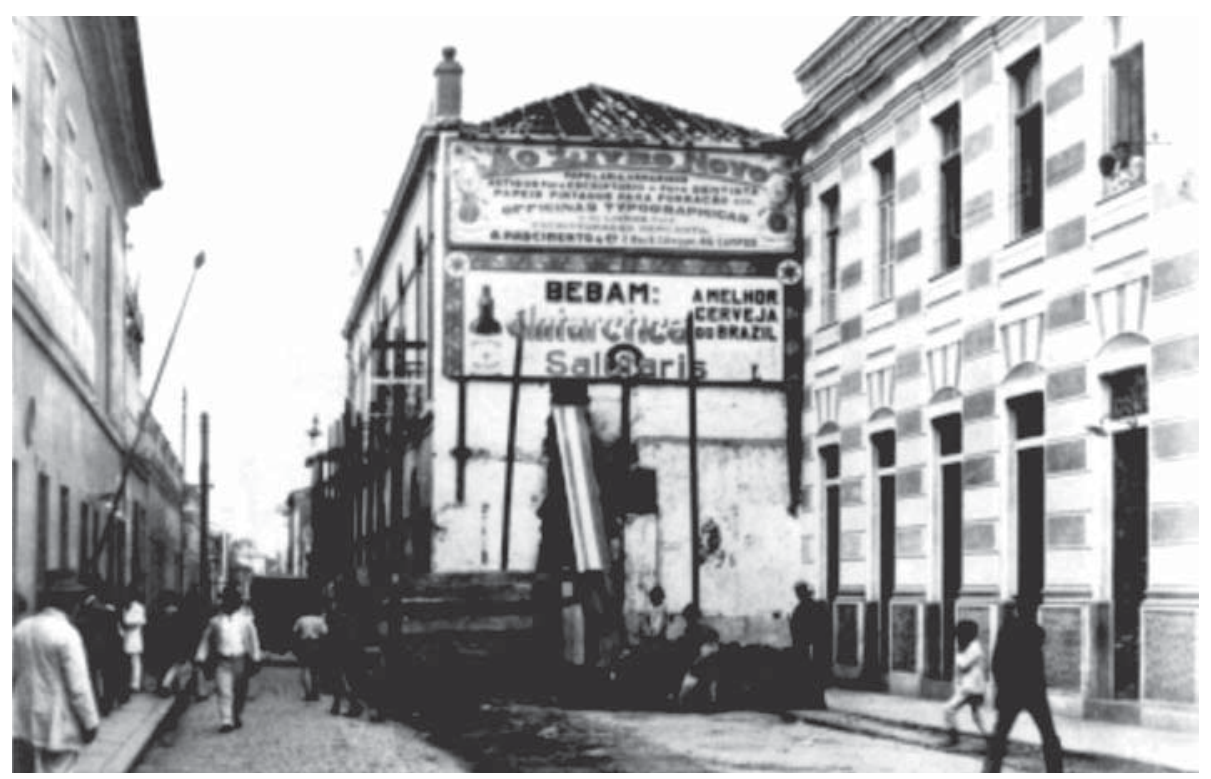

Fotógrafo: Autor não identificado Coleção: Dr. Dario Marinho

Figura 8: O prédio do café High Life situado na nova Rua Sete de Setembro, visto da esquina com o Boulevard Paula Carneiro, 1916.

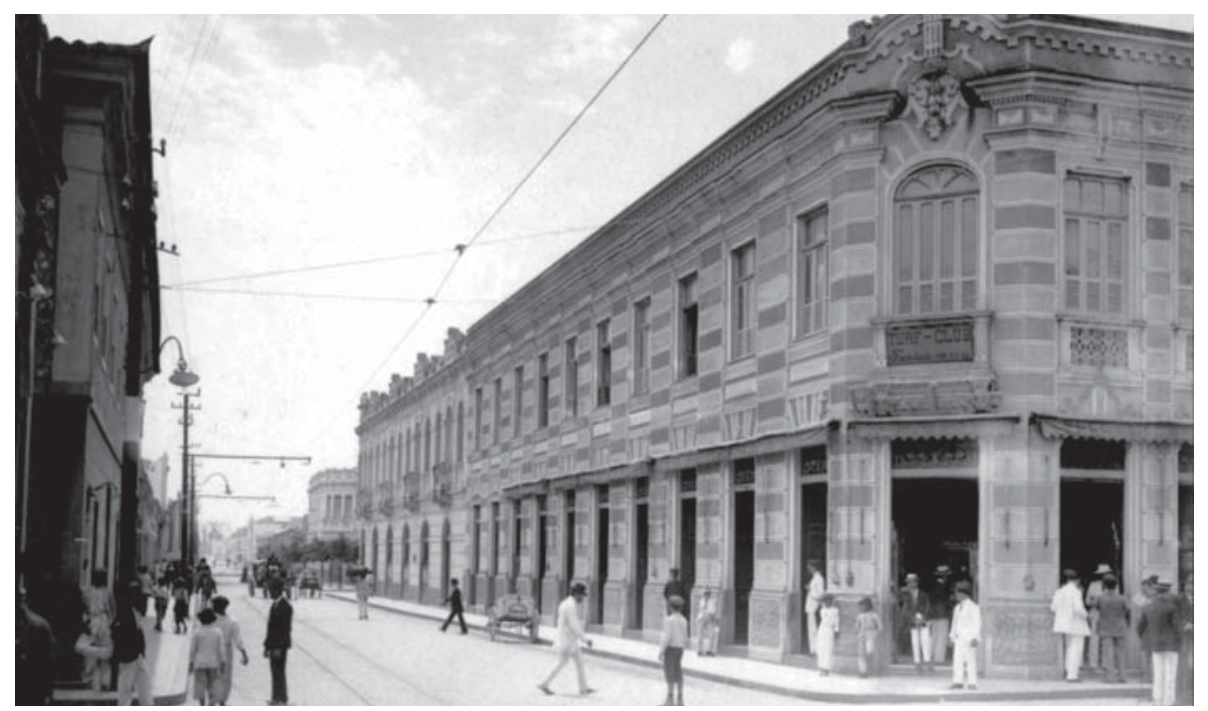

Fotógrafo: A. Ribeiro

Acervo: Biblioteca Municipal Nilo Peçanha / FCJOL 
Figura 9: Término das obras de calçamento da Rua Sete de Setembro. A seguida construção de residências em estilo eclético permite antever o destino reservado à humilde casa colonial à direita.

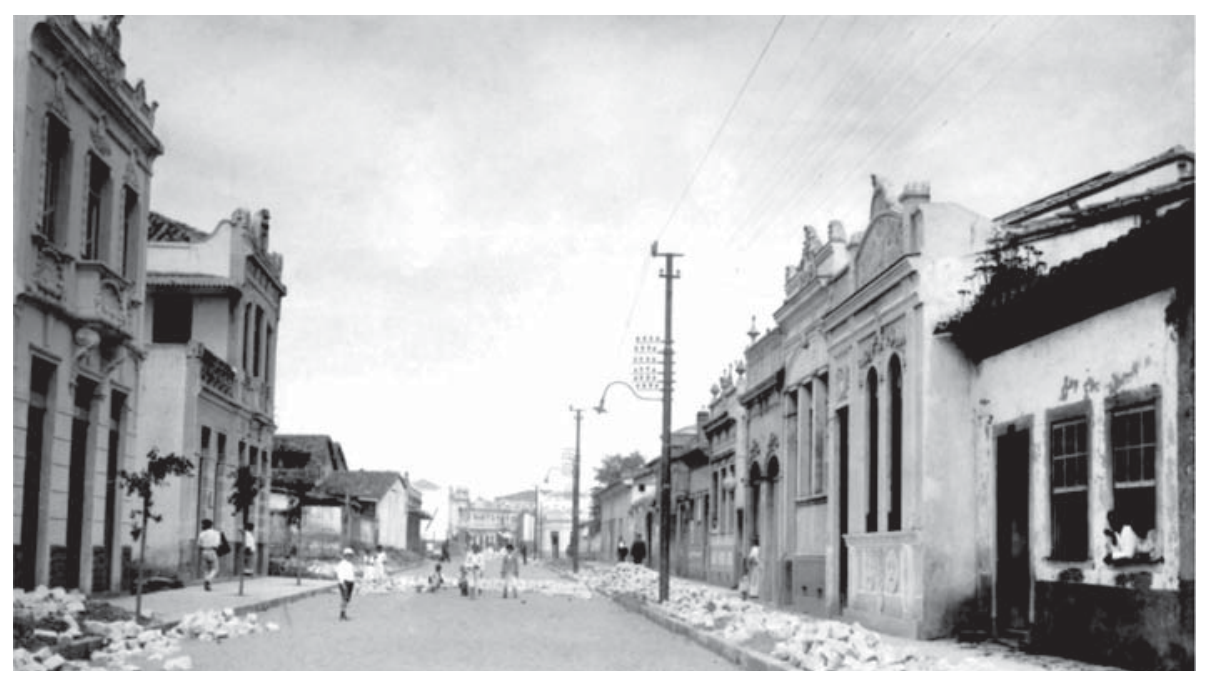

Fotógrafo: A. Ribeiro

Acervo: Biblioteca Municipal Nilo Peçanha / FCJOL

Entre os espaços reurbanizados merecem ser destacados o da Praça Barão do Rio Branco (Jardim do Liceu) (Figura 10), o da Praça Nilo Peçanha (Jardim de São Benedito) (Figura 11) e a Praça das Verduras, agora batizada com o nome de Praça Prudente de Moraes.

O tratamento paisagístico dado à nova Praça Prudente de Moraes afasta definitivamente a ameaça de permanência do mercado em pleno coração da cidade. A esse respeito existe uma clara consonância entre os interesses dos comerciantes do centro de Campos e o Decreto $\mathrm{n}^{\circ}$ 7566, de 23 de setembro de 1909, assinado pelo Presidente Nilo Peçanha ao criar as Escolas de Aprendizes Artífices. O espírito do decreto é o de "proporcionar às classes proletárias os meios de vencer as difficuldades sempre crescentes da lucta pela existência", ou seja, dar educação e principalmente ocupação a essa gente. Em outro ponto o texto do decreto enfatiza: 
Figura 10: A Praça Barão do Rio Branco (Jardim do Liceu) vendo-se em destaque o coreto, 1916.

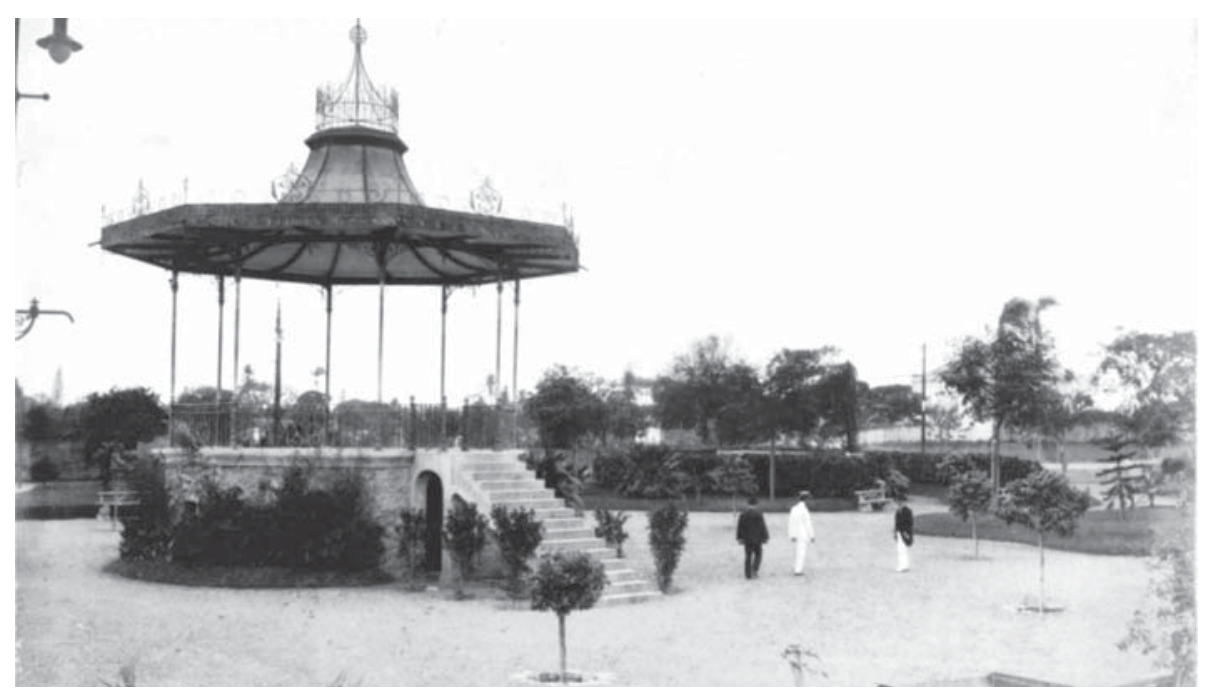

Fotografo: A. Ribeiro

Acervo: Biblioteca Municipal Nilo Peçanha / FCJOL

Figura 11: Postal - A Praça Nilo Peçanha (Jardim S. Benedito) vendo-se ao fundo, à esquerda, a Igreja de S. Francisco, c. 1930.

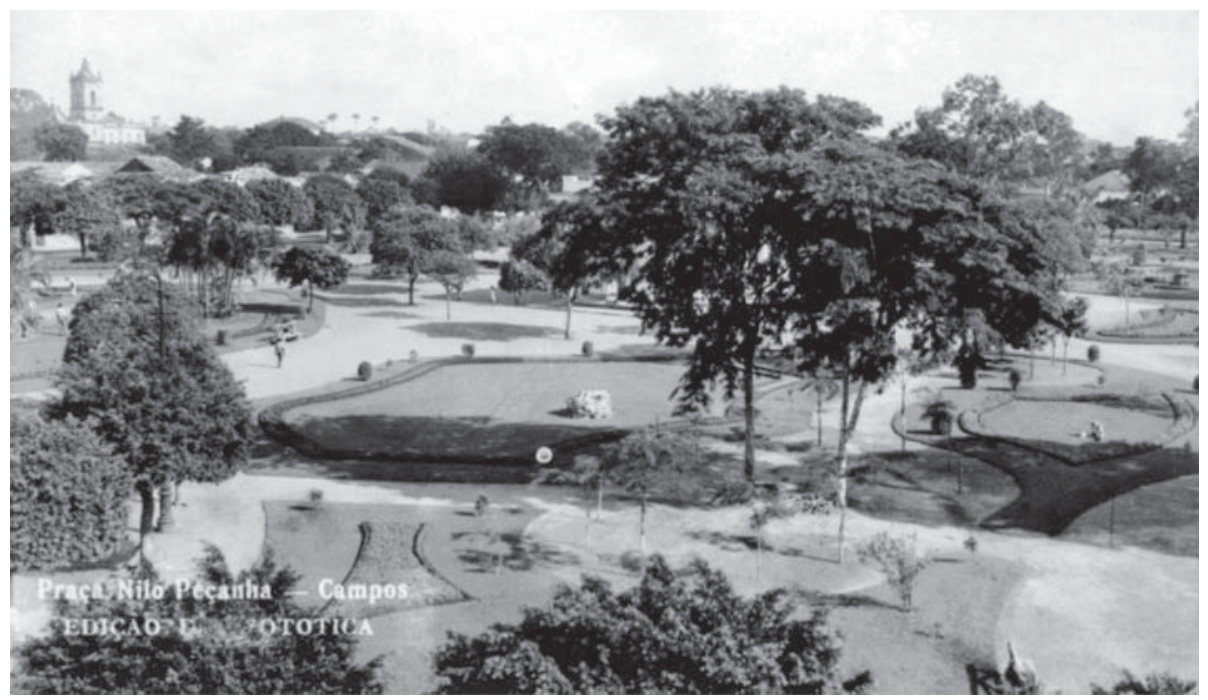

Fotografia: edição da Fototica

Coleção: Leonardo de Vasconcellos Silva 
se torna necessario não só habilitar os filhos dos desfavorecidos da fortuna, com o indispensável preparo technico e intellectual, como faze-los adquirir habitos de trabalho proficuo que os afastará da ociosidade ignorante, escola do vicio e do crime.

A Praça das Verduras, quando se torna Praça Prudente de Moraes, adquire outro status valorizando os estabelecimentos situados no seu entorno. Deixa de ser apenas um local de circulação de pedestres e de trabalhadores menos qualificados para se tornar um novo espaço de sociabililidade (Figura 12). O conjunto de fotografias que integram as diversas coleções particulares e acervos das instituições públicas campistas permite acompanhar a paulatina decadência desse espaço que, durante tanto tempo, foi ponto de referência afetiva para os frequentadores do centro da cidade.

Figura 12: Postal - Interior da livraria Ao Livro Novo, ponto de encontro regular para advogados e funcionários de cartório que trabalhavam no centro de Campos, c. 1910.

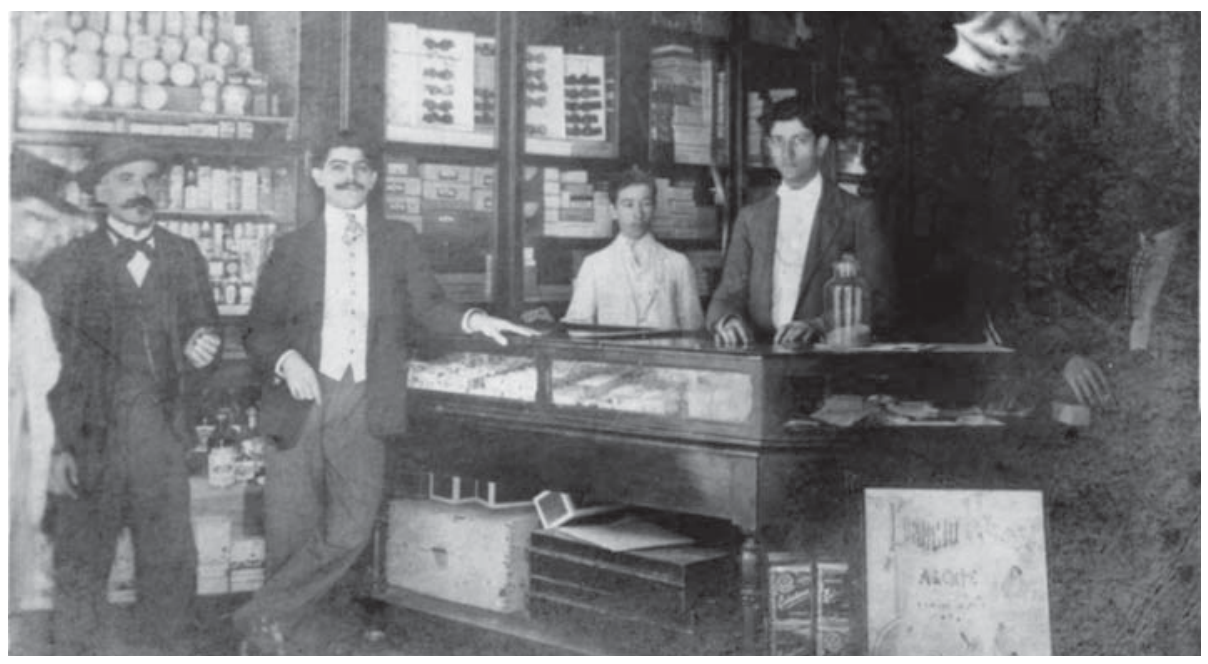

Fotógrafo: T. Bolckau

Coleção: Leonardo de Vasconcellos Silva

\section{OS CARTÕES POSTAIS MUDAM O STATUS DA PRAÇA DAS VERDURAS}

A grande transformação da Praça Prudente de Moraes em 1916, ano em que o presidente da República Wenceslau Braz e o presidente do Estado do Rio de Janeiro Nilo Peçanha vieram a Campos inaugurar as obras empreendidas pela Commissão de Saneamento, coincide com o incremento da atividade fotográfica 
nas primeiras décadas do século XX. A necessidade de difundir as belezas naturais e as transformações urbanísticas das cidades com o auxílio dos cartões postais é um hábito assumido universalmente.

Os primeiros cartões postais que colocam a cidade de Campos como protagonista começaram a circular pouco antes de 1910. Imagens da cidade produzidas pelo fotógrafo amador Francisco de Paula Carneiro foram coloridas a mão e levadas para a Holanda pelo historiador Alberto Frederico de Moraes Lamego, onde foram transformadas em postais e hoje fazem parte da coleção das tradicionais famílias campistas. Ao contrário do espírito que dominaria pouco depois os colecionadores, os postais com fotos de Paula Carneiro, popularmente conhecido como Capitão Carneirinho, não mostravam uma cidade atraente, que despertasse curiosidade em potenciais turistas por sua beleza. Nesta série, os postais que mais faziam sucesso entre os que os adquiriam eram os que retratavam a grande cheia do rio Paraíba no ano 1906, uma das que mais danos causou ao casario da cidade e que somou maior número de vítimas ao seu final.

\section{UMA LINHA DO TEMPO IMAGÉTICA DE CAMPOS DOS GOYTACAZES}

Parte integrante da Fundação Cultural Jornalista Oswaldo Lima, a Biblioteca Municipal Nilo Peçanha possui diversos álbuns de imagens em seu acervo. Entre eles merece destaque o que foi produzido para marcar o fim das obras de infraestrutura e embelezamento pelas quais passou a cidade sob a tutela da Commissão de Saneamento. Este álbum contém uma dedicatória ao presidente Wenceslau Braz:

Lembrança de sua visita a Campos pela inauguração das obras de reforma da Cidade, com os lucros da exploração da terra.

5 de novembro de 1916

Como todo álbum produzido com idêntica finalidade, este também só apresenta os registros positivos do processo de modificação do perfil da cidade. As obras de embelezamento recebem grande destaque, ao passo que os incômodos causados pelas desapropriações e transferência de moradores mais carentes para a periferia da cidade sequer são mencionados. A contratação do fotógrafo A. Ribeiro para esta função deixa claro o resultado que se deseja alcançar. Junto com Augusto Malta, A. Ribeiro atuou no registro do embelezamento pelo qual 
passou a capital federal do Brasil durante a gestão Pereira Passos. Até hoje os postais do Rio de Janeiro por ele editados são objeto de desejo de uma infinidade de colecionadores.

A. Ribeiro se esmerou no álbum dedicado a Campos. Ainda hoje as fotografias feitas por ele provocam observações elogiosas vindas de todos os que se admiram com a beleza que a cidade exibia naquela ocasião. A produção de álbuns fotográficos com a finalidade de tornar públicas as obras executadas por grupos políticos era algo relativamente comum em todos os âmbitos:

As propagandas do estado, por meio dos álbuns, estão comprometidas com os interesses de grupos políticos dominantes que desejavam se perpetuar no poder pelas representações, e não pelas ações. As imagens dos álbuns soam como um tênue limite entre realidade e representação, pois os álbuns enfatizaram imagens de monumentos arquitetônicos do século XVIII, os retratos dos homens públicos e algumas cenas bucólicas (MIRANDA, 2008, p. 20).

O conjunto de imagens analisadas neste texto mostra o apogeu da Praça Prudente de Moraes, sua progressiva degradação e finalmente a sua descaracterização atual. A imagem de 1916 (Figura 13), que inicia esta linha do tempo imagética, sai das lentes de A. Ribeiro. Nela é possível observar a praça já arborizada, equipada com bancos com motivos fitomorfos, postes de ferro batido e bebedouro. O prédio claro em destaque ocupa o lugar do primitivo mercadinho da Praça das Verduras. Dois sobrados em estilos art nouveau e eclético ainda passam pelos últimos retoques.

Figura 13: A Praça Prudente de Moraes já reurbanizada com alguns prédios recebendo os últimos retoques antes de entrar em funcionamento, 1916.

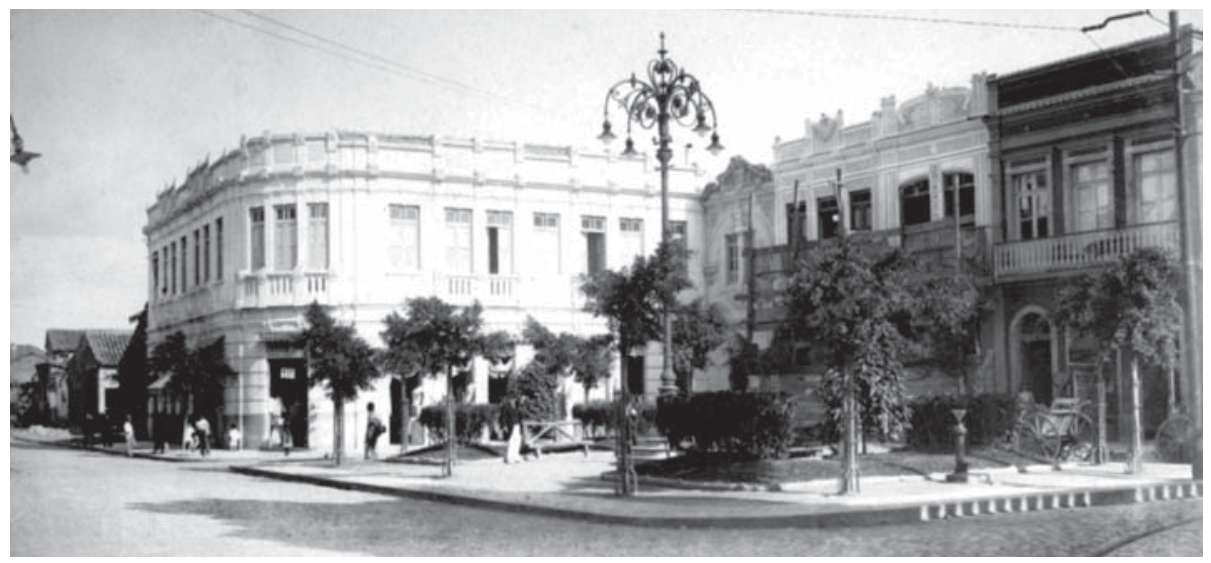

Fotógrafo: A. Ribeiro

Acervo: Biblioteca Municipal Nilo Peçanha / FCJOL

Novos Cadernos NAEA • v. 16 n. 1 • p. 191-210 • jun. 2013 
Uma fotografia (Figura 14), transformada em postal pouco tempo depois, ainda mostra a praça em sua plenitude. A data provável é 1920.

Figura 14: Postal - A Praça Prudente de Moraes em seu apogeu, poucos anos depois de ser inaugurada, c. 1920.

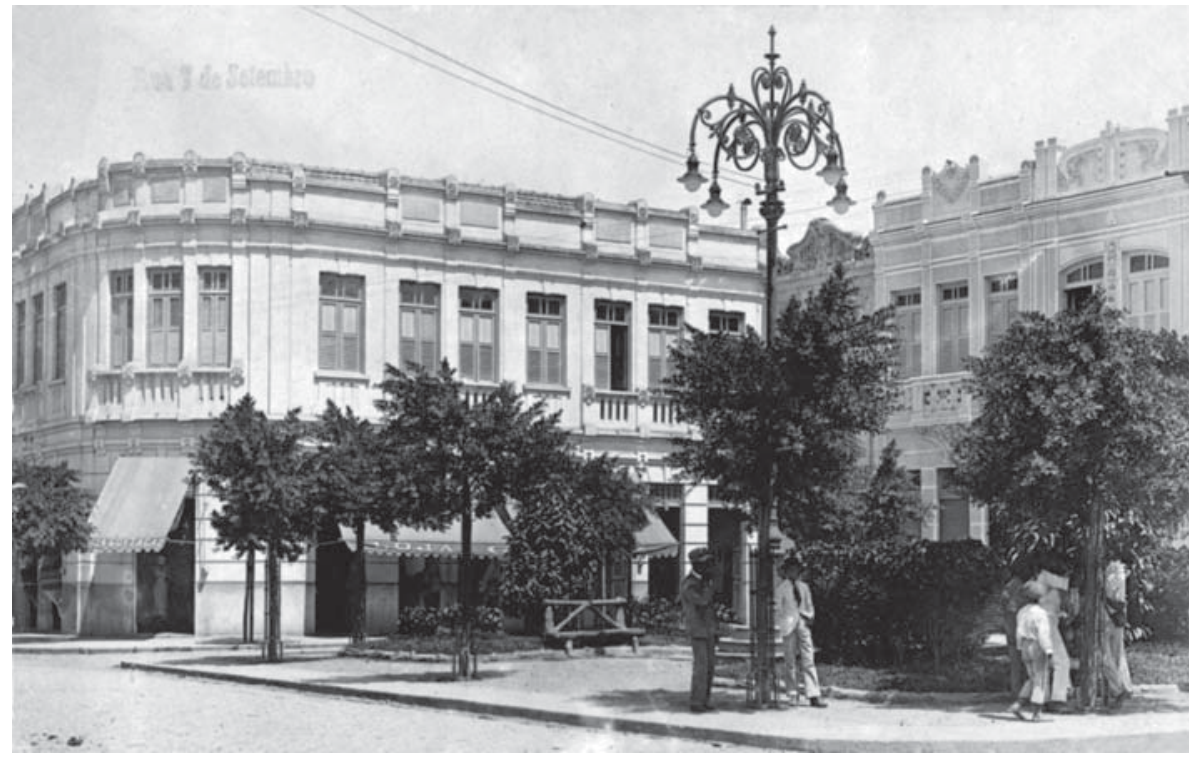

Foto: Autor não identificado

Coleção: Leonardo de Vasconcellos Silva

Em outro postal, com edição da "Fotóptica" (Figura 15), provavelmente de meados da década de 1930, já é possível observar alguns sinais de degradação. Do ponto de vista econômico, a cidade não vivia um grande momento. A produção açucareira havia sofrido um grande baque provocado pela queda da bolsa de Nova Iorque em 1929, causando uma recessão aguda em todo o país e que atingiu grande parte dos fazendeiros e usineiros locais. A diminuição na arrecadação de tributos pode justificar a dificuldade encontrada pela prefeitura para manter bem conservados os espaços públicos. Além das luminárias do poste sem as cúpulas, a presença de bombas de gasolina na calçada da praça certamente reduz uma parcela do seu encanto. 
Figura 15: Postal - A Praça Prudente de Moraes começando a dar os primeiros sinais de degradação, c. 1935.

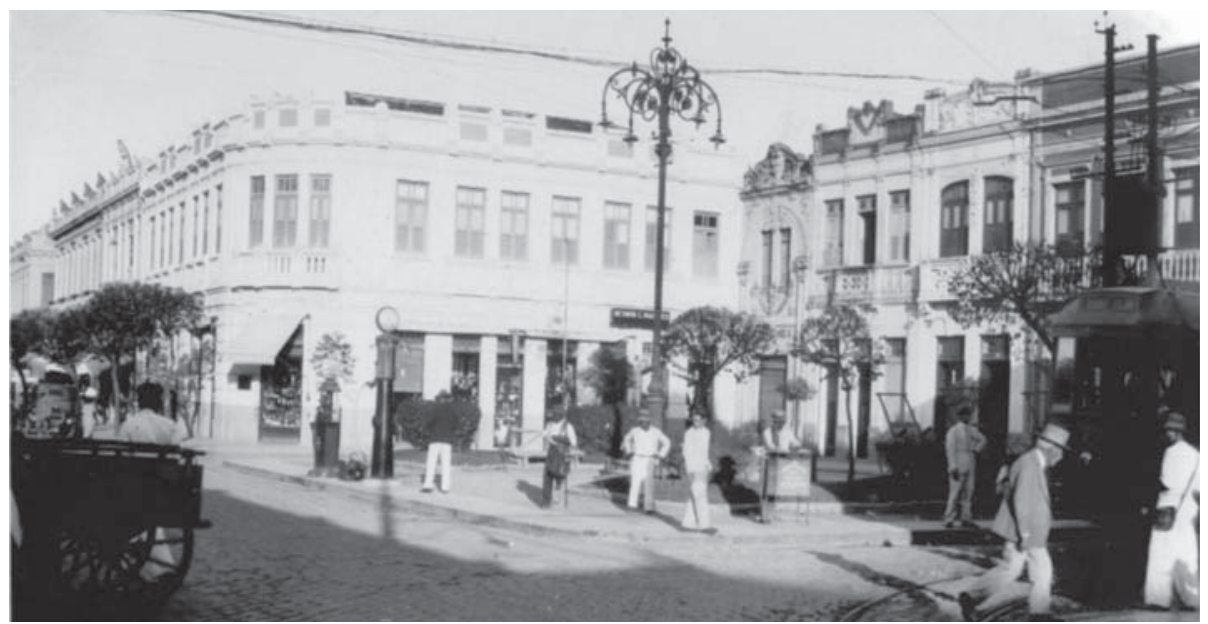

Fotografia: edição da Fotóptica

Acervo: Biblioteca Municipal Nilo Peçanha / FCJOL

A transformação observada menos de uma década depois é radical (Figura 16). Os únicos elementos mantidos são o poste, com design característico do período do Estado Novo, e as bombas de gasolina que dominam o cenário da praça totalmente desnudada e sem nenhum atrativo humano. Os veículos que aparecem estacionados provavelmente são "carros de aluguel", nomenclatura usada em Campos que antecedeu aos "carros de praça" e aos atuais táxis.

Figura 16: Postal - Imagem da Praça Prudente de Moraes sem mais nenhum vestígio da sua configuração original, c. 1940.

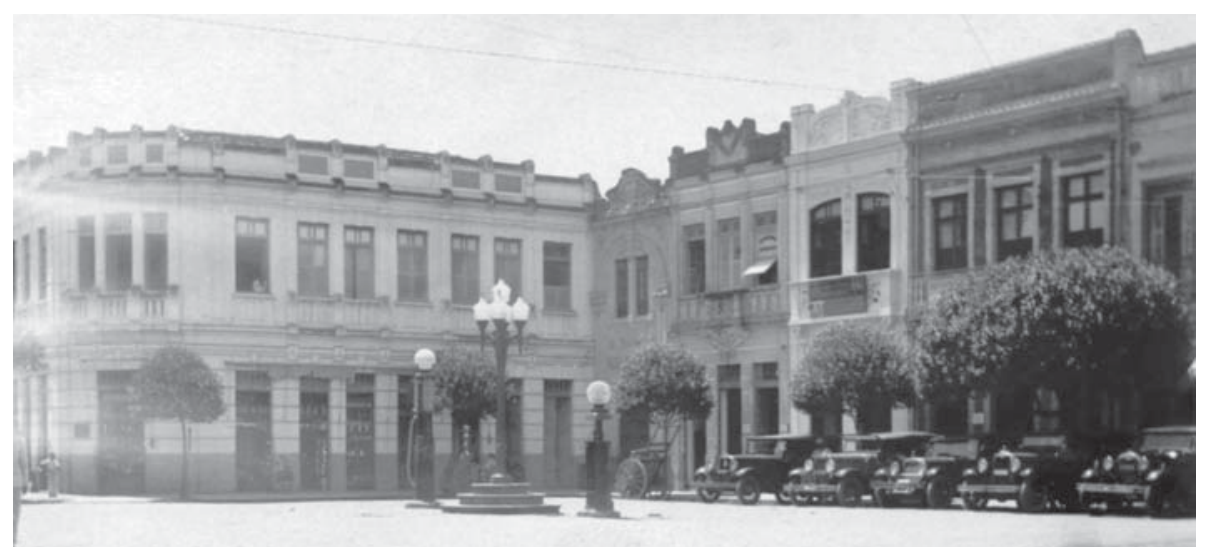

Fotógrafo: Autor não identificado

Acervo: Biblioteca Municipal Nilo Peçanha / FCJOL

Novos Cadernos NAEA • v. 16 n. 1 • p. 191-210 • jun. 2013 
O postal editado pela Foto Chic (Figura 17) mostra uma praça irreconhecível se comparada à original. Para acompanhar as soluções urbanísticas dos grandes centros, foi construído um ponto de ônibus similar aos que existiam no Rio de Janeiro. Esse tipo de estrutura de concreto armado recebeu dos cariocas o apelido de "tabuleiro da baiana" por seu formato, tabuliforme, similar às mesinhas que as baianas usavam para vender seus quitutes. Na Figura, além do sistema de transporte coletivo que começa a se intensificar na região central da cidade, impressiona a quantidade de "carros de praça" que ocupam todos os espaços anteriormente reservados aos pedestres.

Figura 17: Postal - Fotografia da Praça Prudente de Moraes vendo-se em destaque ao centro o ponto de ônibus em forma de "tabuleiro da baiana" que deu origem ao quiosque do Chá-Chá-Chá, c. 1950.

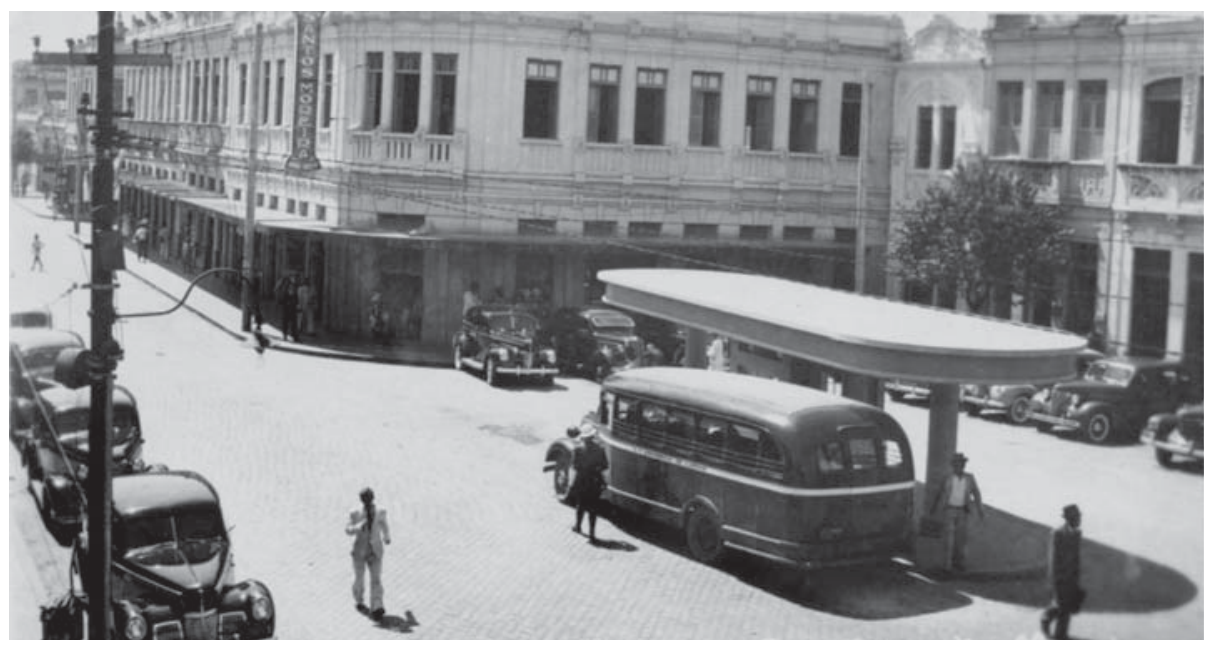

Edição: Foto Chic

Coleção: Leonardo de Vasconcellos Silva 
Figura 18 e 19: Praça do Chá-Chá-Chá
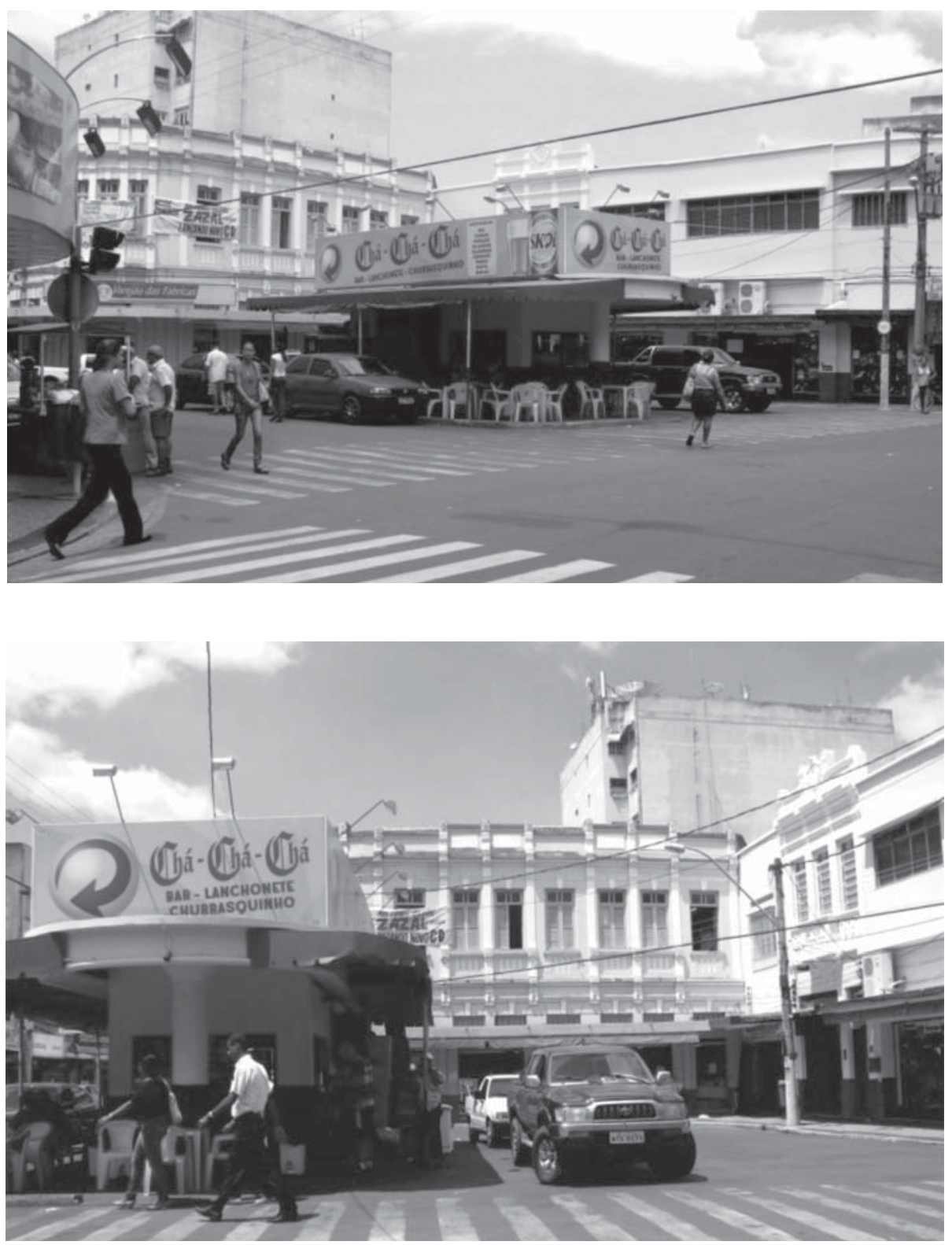

Fotógrafo: Elis Miranda, setembro 2011

$\mathrm{Na}$ etapa seguinte ocorre uma mudança de nomenclatura, passando a Praça Prudente de Moraes a ser chamada de Praça do Chá-Chá-Chá. Não é uma mudança oficial estabelecida pela câmara ou pela prefeitura. $\mathrm{O}$ "tabuleiro da baiana" que servia de ponto de ônibus foi metamorfoseado em lanchonete

Novos Cadernos NAEA • v. 16 n. 1 • p. 191-210 • jun. 2013 
ou, se usarmos a denominação atual, foi transformado em quiosque. O nome da lanchonete, que teve uma razão especial para ser escolhido, acabou se estendendo a todo o espaço ao seu redor: com as atenções voltadas para Cuba, que dominava o noticiário com a recente revolução capitaneada por Fidel Castro e Che Guevara, um ritmo caribenho tomou conta do universo musical no início dos anos 1960. Surgido na ilha, o chá-chá-chá passou a ser presença obrigatória em todas as festas e pistas de dança do mundo. O crescimento desordenado da cidade torna-se cada vez mais acentuado e a Praça do Chá-Chá-Chá não ficou imune a este processo de degradação urbana (Figura 18 e 19). Os táxis permanecem dominando o entorno da praça e o quiosque, sem espaço físico nem infraestrutura para atender de forma confortável a sua clientela, acaba transformando em privado um espaço que deveria permanecer público.

\section{CONSIDERAÇÕES FINAIS}

A reconstituição de contextos a partir da análise de imagens constitui-se um método para os estudos de geo-história, planejamento urbano, de estudos de paisagens e tantos mais forem a imaginação geográfica. Neste texto enfatizamos um recorte espacial para demonstrarmos o quanto um espaço de sociabilidade passou por diferentes usos em diferentes momentos históricos. Demonstramos que seus usos estavam relacionados a contextos locais, mas sempre articulados a fenômenos interescalares. Verifica-se que a inércia da sociedade campista em relação ao processo de degradação dos espaços públicos e, em especial de seu centro histórico é o aspecto que causa maior estranheza aos que o vivem e aos que passam por Campos dos Goytacazes na atualidade. Estranheza por se tratar de um município beneficiado por rendas de royalties e participações especiais provenientes da indústria petrolífera e que, portanto, poderia investir recursos na preservação da sua história, por meio da restauração de prédios históricos, do investimento em instituições de memória e de produção cultural que enfatize os diferentes momentos históricos que esta cidade viveu e contribua para o desenvolvimento social não apenas da cidade, mas da região Norte Fluminense.

\section{REFERÊNCIAS}

BAEPENDY, V. de. Autorização para contratar companhia ou emprezario para construção do mercado público. In: CARNEIRO, M.B.S. Atos e fatos da antiga Campos. Campos dos Goytacazes: Edição da autora, 1985. 
HALL, P. Cidades do amanhã: uma história intelectual do planejamento e do projeto urbanos do século XX. São Paulo: Perspectiva, 2009 [1988].

KOSSOY, B. Origens e expansão da fotografia no Brasil - século XIX. Rio de Janeiro: FUNARTE, 1980.

MIRANDA, E.A. Representações Amazônicas: cultura e ideologia nas imagens dos Álbuns do Estado do Pará. In: FIGUEIREDO, S.L. (Org.). Turismo, lazer e planejamento urbano e regional. Belém: NAEA, 2008.

MONITOR CAMPISTA. Ligeiro histórico sobre os melhoramentos de Campos. Campos dos Goytacazes: [s.n.], 5 nov. 1916.

SOUSA, H. Cyclo Aureo: História do $\mathbf{1}^{\mathbf{0}}$ Centenário de Campos. Campos: Artes Graphicas; Escola de Aprendizes Artífices, 1935. 